\title{
Manipulación genética y el estudio del parásito protozoario Leishmania
}

\author{
Tania M. Cortázar, John Walker \\ Centro Internacional de Entrenamiento e Investigaciones Médicas, CIDEIM, Cali, Colombia.
}

Durante los últimos 15 años se ha dado paso al entendimiento de muchos aspectos de la genómica funcional de Leishmania gracias a los avances en la metodología de transfección de ADN dentro de la célula de este protozoario, la eliminación y la complementación de genes por medio de recombinación homóloga y las estrategias para la selección de células transfectadas. Estos acercamientos tienen el potencial de brindar información sobre la expresión génica y la función de las proteínas en el contexto del parásito intacto. Dado que el genoma de Leishmania muestra una carencia acentuada de los factores conocidos de iniciación de la transcripción y que la expresión génica está regulada casi completamente a nivel postranscripcional (a través del empalme de los ARNm y los mecanismos que involucran el procesamiento diferencial de la región no traducida $3^{\prime}$ del ARNm (3'UTR), la transfección génica representa una herramienta útil para la identificación y el análisis funcional de los genes de interés así como de los mecanismos que dirigen su regulación.

El desarrollo de los sistemas de manipulación genética también ha abierto nuevos horizontes para la identificación de genes esenciales involucrados en la virulencia, la supervivencia intracelular y la resistencia a drogas de Leishmania, así como para la validación de proteínas específicas del parásito como nuevos blancos quimio e inmunoterapéuticos. En esta revisión presentamos los avances más recientes en el campo de la manipulación genética en Leishmania, los cuales permiten análisis estructurales, funcionales y de fenotipo, por medio de la eliminación y complementación génica a través de la transfección transitoria o permanente de genes en este parásito.

Palabras clave: Leishmania, transfección de ADN, expresión génica, eliminación y complementación génica, genómica funcional.

\section{Genetic manipulation and the study of the protozoan parasite Leishmania}

During the last 15 years, many aspects of the functional genomics of Leishmania have been revealed due to advances in DNA transfection, gene disruption and complementation through homologous recombination, and efficient strategies for the selection of transfected cells. These strategies have provided information about gene expression and protein function in the context of the intact parasite. The genome of Leishmania shows a marked deficiency of known transcription initiation factors, and gene expression is regulated almost entirely at the posttranscriptional level through trans-splicing of mRNAs and novel control mechanisms involving differential processing of $3^{\prime}$ - untranslated regions ( $\left.3^{\prime}-U T R s\right)$ of mRNAs. Therefore, gene transfection represents a useful tool for the identification and functional analysis of genes of interest as well as the mechanisms that direct their regulation. The development of genetic manipulation systems has provided opportunities for the study of genes involved in virulence, intracellular survival and drug resistance of Leishmania, as well as for the functional validation of specific parasite proteins as new chemo- and immunotherapeutic targets. The current review presents recent advances in genetic manipulations that permit structural, functional and phenotypic analyses and by means of gene deletion and complementation using the methods of gene transfection.

Key words: Leishmania, DNA transfection, gene expression, gene deletion and complementation, functional genomics. 
Leishmania es el parásito intracelular causante de la leishmaniosis, una de las enfermedades de mayor impacto en salud pública, distribuida alrededor del mundo con 15 millones de personas infectadas y 350 millones más en riesgo (1). Esta enfermedad presenta un rango amplio de síntomas clínicos en el que se incluyen desde lesiones cutáneas autocurables hasta lesiones mucosas y compromisos viscerales fatales, que dependen de las interacciones entre la respuesta inmune del hospedero y la especie de Leishmania involucrada.

Leishmania infecta fagocitos mononucleares, componentes celulares claves del sistema inmune. La quimioterapia es el único medio para el control de leishmaniosis ya que no existe una vacuna efectiva. Sin embargo, la eficacia de las drogas en algunos casos es limitada debido al incremento de la falla clínica al tratamiento con los agentes antimoniales (tratamiento estándar para la leishmaniosis), y a la toxicidad de los medicamentos de segunda línea (2-4). La miltefosina se presenta como una futura alternativa promisoria para el tratamiento de la leishmaniosis visceral, y es el único tratamiento oral hasta con $98 \%$ de efectividad en el control de esta enfermedad $(3,4)$. Por ello se hace necesaria la búsqueda de nuevas estrategias que permitan un mayor conocimiento de la interacción del parásito con la célula hospedera. Los avances en las técnicas de manipulación genética junto con el proyecto genoma [www.ebi.ac.uk/parasites/ leish.html] y el desarrollo de la genómica funcional representan herramientas útiles para enlazar el genotipo y el fenotipo de Leishmania, lo cual permite avances en la identificación y valoración de nuevos blancos quimio e inmunoterapéuticos.

El uso de la tecnología de transfección de ADN en Leishmania comenzó con la expresión transitoria de genes luego de la electroporación

Correspondencia:

John Walker, Centro Internacional de Entrenamiento e Investigaciones Médicas, CIDEIM, Avenida 1 Norte No. 303, AA 5390, Cali, Colombia.

Teléfono: (572) 668 2164; fax: (572) 6672989.

john_walker@ cideim.org.co

Recibido: 08/07/04; aceptado: 01/10/04 de parásitos con vectores circulares (5), y se ha desarrollado hasta incluir un espectro amplio de métodos para el análisis funcional de genes que han permitido estudiar la expresión y la regulación génica del parásito (6-27), la identificación de genes esenciales para supervivencia (28-49), la investigación de los mecanismos de resistencia a drogas y de virulencia (50-92), la producción de proteínas foráneas (91-107), la identificación y la expresión de antígenos de superficie (108). En la presente revisión se divulgan los avances y aplicaciones más recientes y notorias en el campo de la manipulación genética en Leishmania.

\section{Transfección}

La introducción de fragmentos de ADN dentro de una célula eucariota que inducen un cambio en la expresión génica se denomina transfección. La transfección de genes se logra luego de someter las células a procedimientos mediante los cuales las membranas celulares son permeabilizadas temporalmente y permiten la toma de ADN. Hay dos tipos básicos de técnicas de transfección: los métodos químicos, basados en la formación de complejos de ADN con compuestos como fosfato de calcio, o N,N-dietilaminoetildextrano, los cuales son incorporados por las células mediante la ruta endocítica, o por afinidad con las membranas celulares (lipofección); y los métodos físicos, basados en la introducción mecánica de las moléculas al interior de la célula (microinyección, electroporación, biolistic particle delivery) (109). La eficiencia de una transfección puede variar entre y dentro de especies de protozoarios, y las condiciones técnicas óptimas deben ser determinadas para cada cepa y estadio. Entre los parámetros variables para las transfecciones de Leishmania por medio de electroporación, por ejemplo, se incluyen el voltaje y el tiempo del pulso utilizado, la fuerza iónica del tampón, la densidad celular, la cantidad de ADN y las condiciones de selección de las células transfectadas (103-107,110).

\section{Transfección transitoria y el estudio de la regulación de la expresión génica en Leishmania}

El uso de la transfección transitoria de Leishmania se ha dirigido principalmente al análisis rápido de 
la transcripción y la regulación postranscripcional, debido a que Leishmania (y otros miembros de la familia Trypanosomatidae) posee un genoma con características poco ortodoxas en su organización y expresión, en comparación con la mayoría de los eucariotes (6-23). En Leishmania y Trypanosoma muchos genes se encuentran agrupados en unidades de transcripción policistrónicas que hacen que cada transcrito primario sea un ARNm precursor policistrónico (8) (figura 1). Los ARNm individuales son escindidos del precursor por medio de una reacción de trans-empalme, durante la cual una secuencia líder de 39 nucleótidos (miniexón, ME) se une a cada uno de los transcritos en el extremo 5'-, donándoles la estructura cap (residuo 7metilguanosina) al mismo tiempo que el extremo 3'- de cada mARN es poliadenilado y generan así los ARNm maduros $(9,111)$. Las unidades policistrónicas pueden contener múltiples copias de un gen en tandem, así como también genes relacionados o no relacionados entre sí (8).

Durante los experimentos de transfección se ha observado que los requisitos para la expresión génica en Leishmania no son rigurosos. En la mayoría de los eucariotes, los genes que codifican para proteínas son transcritos por la ARN polimerasa II (Pol II) $(112,113)$. Sin embargo, en Leishmania no se ha identificado ningún promotor específico para Pol II y la transcripción de genes a partir de vectores tampoco requiere de este promotor (104-107). Los genes tripanosomátidos carecen de intrones, pero existe una dependencia importante de la presencia de las regiones intergénicas para la expresión de genes, lo cual indica que éstas contienen las señales necesarias para la transcripción y la maduración del ARNm (6-23). Por ello, para la expresión transitoria de genes en Leishmania se usan vectores de expresión circulares que contengan la secuencia a.

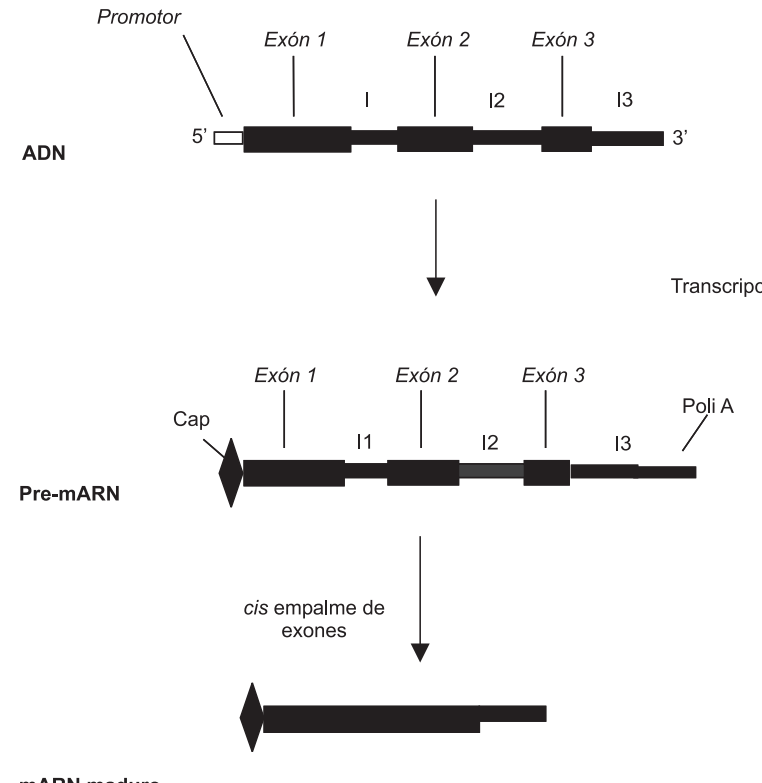

b.
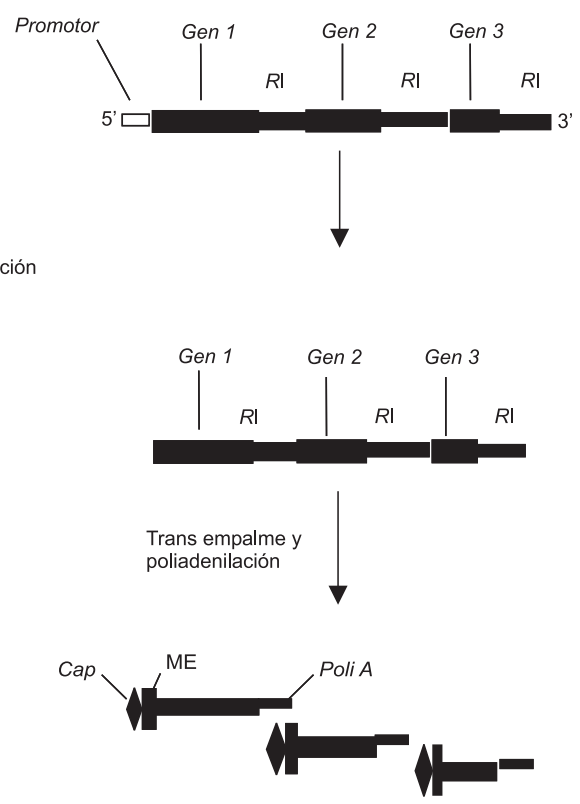

Figura 1. Diferencias entre la biogénesis del mARN en Leishmania y otros eucariotes (adaptada de 8). a. Durante la biogénesis del ARN en la mayoría de los organismos eucariotes se requiere de cis-empalme para remover las secuencias no codificadoras (intrones) de los transcritos primarios. b. Los tripanosomátidos generan transcritos monocistrónicos a partir del trans-empalme de las unidades de transcripción policistrónicas. En los tripanosomátidos, la estructura cap es donada por ME.

I: intrón; cap: residuo de 7-metilguanosina; poli A: sitio para la poliadenilación en el extremo 3’ del transcrito; RI: región intergénica; ME: miniexón 
de un gen reportero flanqueado por regiones intergénicas del parásito (figura 2a). En los estudios de transfección de células de Leishmania reportados hasta la fecha, el producto génico se muestra activo y, en ocasiones, sólo un fragmento de la región intergénica es necesario para la expresión del gen (cuadro 1).

El genoma de Leishmania contiene secuencias de iniciación de la transcripción divergentes de las conocidas en otros eucariotes, y éstas han sido explotadas como herramientas en el diseño de vectores de transfección. Por ejemplo, una expresión más eficiente se logra al incluir en el vector secuencias promotoras para la Pol I, como el promotor del ARN ribosómico (ARNr) o el de ME (24-27) (figura 2a). El promotor de ARNr de la subunidad $18 S$ de $L$. chagasi ha dirigido la sobreexpresión de proteínas funcionales con distintos grados de actividad entre las especies $L$. donovani,
L. major, L. mexicana y L. enriettii, y carece de actividad en $T$. cruzi, sustentando una actividad especie-específica (27).

Se ha reportado la expresión de genes de especies homólogas a partir de vectores de expresión. Por ejemplo, la fosfatasa ácida de secreción (SAP) y la glicoproteína de membrana Gp46/M2 de $L$. mexicana han sido expresadas por células de $L$. major (108). Además, se ha observado que Leishmania puede expresar genes flanqueados con secuencias intergénicas de T. cruzi, y se han construido vectores que pueden expresar productos génicos en ambos parásitos. Sin embargo, no se han obtenido productos de la transcripción de estos vectores en otros tripanosomátidos como Trypanosoma brucei brucei y Crithidia fasiculata $(104,105)$, sugiriendo la posible transición evolutiva desde una iniciación específica de la transcripción en tripanosomátidos

a.

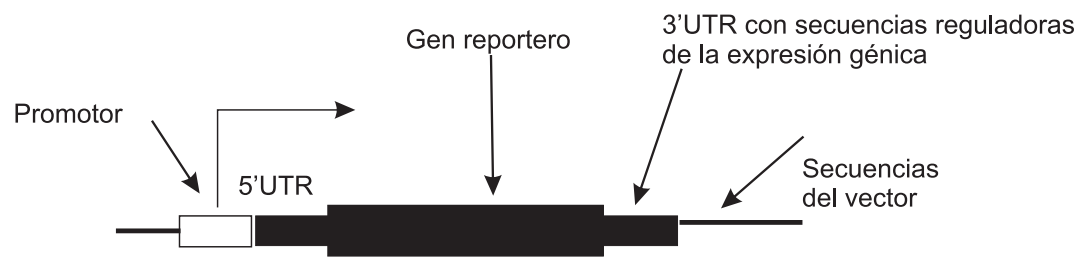

b.
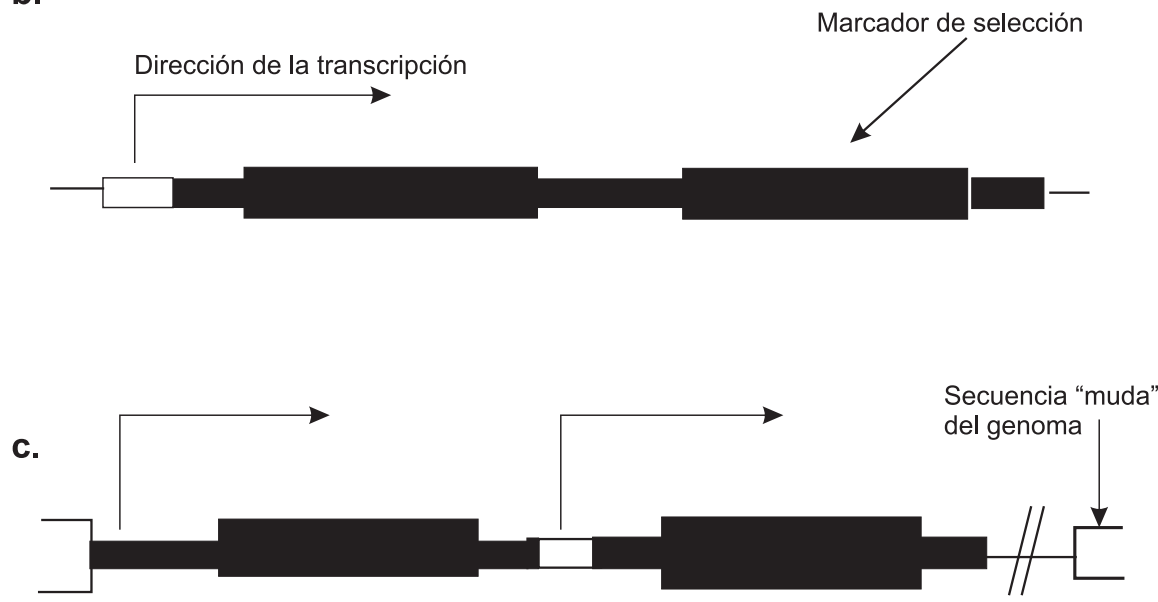

Figura 2. Vectores de expresión usados en la transfección de Leishmania. a. Vector de expresión con gen reportero y secuencias 5'- y 3'-UTR de Leishmania para transfecciones transitorias. La 3'-UTR de los genes de Leishmania posee las secuencias reguladoras de la expresión génica. b. Vector con marcador de selección para transfecciones permanentes. c. Plásmido lineal con promotor, útil en la transfección permanente por integración al genoma durante la recombinación homóloga en ensayos de deleción y complementación. La presencia del promotor en a. y b. es opcional. 
Cuadro 1. Genes transfectados en Leishmania.

\begin{tabular}{|c|c|c|c|}
\hline Gen transfectado & Secuencias intergénicas & Especie transfectada & Referencias \\
\hline$h s v-t k$ & $\mathrm{~A} 2$ & L. donovani & 96 \\
\hline$h s v-t k$ & A2 & L. major & 97 \\
\hline cat & $\alpha$-tubulina & $\begin{array}{l}\text { L. brasiliensis } \\
\text { L. enriettii } \\
\text { L. major }\end{array}$ & 5 \\
\hline cat & $\alpha$-tubulina & L. enriettii & 6 \\
\hline$n e o^{r}$ & $d h r-t s$ & L. major & 29,107 \\
\hline neor & $\alpha$-tubulina & L. enriettii & 103 \\
\hline$n e o^{r}$ & ptr1 & L. major & 106 \\
\hline$n e o^{r}$ & gapdh de T. cruzi & L. mexicana & 102 \\
\hline \multicolumn{4}{|l|}{ L. donovani } \\
\hline hyg $g^{r}$ & ptr1 & L. major & 106 \\
\hline$p^{r}$ & ptr1 & L. major & 106 \\
\hline phleor & ptr1 & L. major & 106 \\
\hline N-acetil glucosaminil transferasa & ptr1 & L. major & 106 \\
\hline A2 antisentido & $A 2$ & L. donovani & 84 \\
\hline 3'nt/un & $\mathrm{A} 2$ & L. donovani & 96 \\
\hline gp46/M2 de L. amazonensis & $d h r-t s$ & L. major & 108 \\
\hline tryA de $T$. cruzi & - & L. donovani & 33 \\
\hline luc & gp63 & L. chagasi & 85 \\
\hline luc & $\alpha$-tubulina & $\begin{array}{l}\text { L. donovani } \\
\text { L. major }\end{array}$ & 100 \\
\hline luc & promotor de rARN $18 S$ & $\begin{array}{l}\text { L. chagasi } \\
\text { L. donovani } \\
\text { L. major } \\
\text { L. mexicana }\end{array}$ & 27 \\
\hline luc & $\alpha$-tubulina & L. infantum & 99 \\
\hline $\operatorname{mos} 1$ & dhfr-ts & L. major & 98 \\
\hline transposasa de MLE & dhfr-ts & L. major & 98 \\
\hline IFN- $\gamma$ murino & $\alpha$-tubulina & L. major & 93 \\
\hline P53 humana & $\alpha$-tubulina & L. donovani & 94 \\
\hline
\end{tabular}

hsv-tk: timidina cinasa del virus herpes simples; cat: cloranfenicol acetil transferasa bacteriana; neor: neomicín transferasa; $h_{y} g^{r}$ : gen de resistencia a higromicina B; pac': gen de resistencia a puromicina; phleor: gen de resistencia a fleomicina; 3'nt/nu: 3'nucleotidasa/nucleasa; gp46/M2: glicoproteína de membrana; tryA: trypanotión reductasa; luc: luciferasa de luciérnaga; mos1: mariner, elemento transponible de Drosophila; MLE: elementos tipo mariner; IFN- $\gamma$ : interferon gamma; A2: gen amastigote-específico; dhfr-ts: dihidrofolato reductasa timidilato sintasa; ptr1: pteridin reductasa; gapdh: gliceraldehído-3-fosfato deshidrogenasa

africanos, hacia una iniciación inespecífica como en Leishmania (114). En apoyo a la idea anterior se encuentra el hecho de que durante los ensayos de transfección es indispensable la presencia de un promotor de Pol I para la transcripción en $T$. brucei pero no en Leishmania (105).

Los procesos de trans-empalme y poliadenilación están mecánicamente acoplados y poseen señales reguladoras comunes ricas en polipirimidinas dentro de las regiones intergénicas. La región intergénica 5' (5'-RI) posee un sitio AG que actúa como aceptor del SL y se ha observado expresión génica al reemplazar la 5'-RI por un tracto sintético de pirimidinas con uno o dos sitios AG (6). Además, a pesar de la ausencia de las señales consenso específicas que aseguren la poliadenilación del ARNm en Leishmania, el extremo 3' de cada ARNm está poliadenilado a una distancia fija (100-400 nucleótidos) corriente arriba de las señales para el trans-empalme del ME del siguiente gen (9).

Durante su ciclo de vida, Leishmania se mueve entre el tracto alimenticio de un insecto y los fagolisosomas ácidos de los macrófagos de mamíferos (2). La habilidad de sobrevivir en ambientes diferentes depende de la regulación de 
Cuadro 2. Genes eliminados en Leishmania.

\begin{tabular}{|c|c|c|c|}
\hline Categoría & Gen eliminado & Especie & Referencia \\
\hline \multirow[t]{4}{*}{ Organización celular/biogénesis } & $\alpha$-tubulina & L. enriettiil & 43 \\
\hline & pfr1 y pfr2 & L. mexicana & 45 \\
\hline & sherp/hasp & L. major & 64 \\
\hline & Imxmkk & L. mexicana & 39 \\
\hline \multirow[t]{8}{*}{ Metabolismo } & Imxmbap & L. mexicana & 34 \\
\hline & dpms & L. mexicana & 81 \\
\hline & spt2 & L. major & 35 \\
\hline & odc & L. donovani & 47 \\
\hline & spdsyn & L. donovani & 46 \\
\hline & adometdc & L. donovani & 38 \\
\hline & $d h f r-t s$ & L. major & 29,57 \\
\hline & ptr1 & L. major & 65 \\
\hline \multirow[t]{3}{*}{ Transducción de señal } & Impk & L. mexicana & 86 \\
\hline & Imxmkk & L. mexicana & 39 \\
\hline & crk3 & L. mexicana & 30 \\
\hline \multirow[t]{3}{*}{ Transporte } & $\operatorname{pgpA}$ & L. tarentolae & 51 \\
\hline & $b t 1$ & L. donovani & 40 \\
\hline & Idnt2 & L. donovani & 49 \\
\hline \multirow[t]{5}{*}{ Destino de proteínas } & hsp100 & L. major & 91 \\
\hline & $n m t$ & L. major & 28 \\
\hline & $\operatorname{gim} 1$ & L. donovani & 36 \\
\hline & sigma1-adaptina & L. mexicana & 87 \\
\hline & mu 1-adaptina & L. mexicana & 87 \\
\hline \multirow[t]{9}{*}{ Factor de virulencia } & $I m c p b$ & L. mexicana & $71,74,82$ \\
\hline & gp63 & $\begin{array}{l}\text { L. amazonensis } \\
\text { L. major }\end{array}$ & 75 \\
\hline & A2 & L. donovani & 84 \\
\hline & gdpmp & L. mexicana & 79 \\
\hline & pmi & L. mexicana & 78 \\
\hline & Ipg1 y lpg2 & $\begin{array}{l}\text { L. major } \\
\text { L. donovani }\end{array}$ & 76,88 \\
\hline & pmm & L. mexicana & 81 \\
\hline & sigma1-adaptina & L. mexicana & 87 \\
\hline & mu 1-adaptina & L. mexicana & 87 \\
\hline
\end{tabular}

pfr1 y pfr2: proteínas 1 y 2 de la vaina paraflagelar; sherp/hasp: proteína hidrofílica en membrana del retículo endoplásmico y mitocondria/proteína de superficie hidrofílica acilada; Imxmbap: fosfatasa ácida de membrana; dpms: dolicolfosfato manosa sintasa; spt2: subunidad 2 de la serina palmitoil-transferasa; odc: ornitina decarboxilasa; spdsyn: espermidina sintasa; adometdc: S-adenosil metionina decarboxilasa; dhr-ts: dihidrofolato reductasa timidilato sintasa; ptr1: pteridina reductasa 1; Impk: protein cinasa activada por mitógeno; Imxmkk: protein cinasa activada por mitógeno; crk3: serina treonina proteín cinasa relacionada con cdc2; pgpA: proteína de la familia de los transportadores ABC; bt1: transportador de biopterina 1; Idnt2: transportador de nucleósidos 2; hsp100: proteína de choque térmico; nmt: N-miristoil transferasa; gim1: proteína de membrana glicosómica; gp63: metaloproteína de superficie; Imcpb: cisteín proteinasa b; Ipg1: glicosiltransferasa; lpg2: transportador de GDP-manosa; pmm: fosfomanomutasa; gdpmp: GDP-manosa pirofosforilasa; pmi: fosfomanosa isomerasa

una variedad de genes. La regulación de los niveles de ARNm durante el desarrollo en Leishmania está determinada de manera postranscripcional y depende del procesamiento diferencial del ARNm en las 3'-UTR (6-23). Se han encontrado secuencias que regulan la expresión génica en los diferentes estadios. Un elemento de 450 nucleótidos altamente conservado en la 3'UTR de varios ARNm expresados diferencialmente en el estadio intracelular del parásito (amastigote), promueve la traducción específica de éstos al hacer más fuerte su unión a los polisomas; además, el pH ácido es una señal importante para este control (9). Los ensayos con genes reporteros y los estudios de hibridación muestran una correlación alta entre la presencia de este elemento 
corriente abajo del gen reportero y la regulación de la traducción diferencial del ARNm reportero. Aunque el mecanismo molecular por el cual dicho elemento regula la expresión amastigote-específica no está dilucidado, un análisis estructural reveló que éste se pliega en una estructura bipartita en forma de Y que podría facilitar la unión a un factor regulador común de la expresión amastigoteespecífica (9). Igualmente, el análisis de eliminación y el bloqueo llevaron a la identificación del elemento negativo de 10 nucleótidos en la región 3'-UTR del ARNm de PFR2 (proteína 2 de la vaina paraflagelar) de L. mexicana que desestabiliza el ARNm en amastigotes (20). La regulación de los genes metacíclico-específicos cpb1 y cpb2 (cisteína proteinasas lisosómicas 1 y 2) está dada por una secuencia de 120 nucleótidos presente únicamente en la 3'-UTR de estos dos genes, mientras que los 17 isogenes restantes se expresan predominantemente en amastigotes $(16,23)$.

La metodología de transfección representa una herramienta útil para la identificación y análisis funcional de genes estadio-específicos o constitutivos, y para el estudio de los mecanismos que dirigen su regulación. Esto contribuye al conocimiento de los mecanismos de supervivencia intracelular del parásito y al futuro descubrimiento de otros elementos reguladores positivos y negativos dentro de las regiones intergénicas y a la dilucidación de las interacciones entre ellos, así como a la búsqueda de genes que puedan representar blancos terapéuticos.

\section{Transfección estable en Leishmania}

La creación de líneas celulares transfectadas de manera estable es la ruta preferida para la mayoría de los estudios cuantitativos y funcionales. En 1990 se reportaron los primeros sistemas de transfección permanente en Leishmania. Los ARNm transcritos a partir del ADN plasmídico contenían el ME unido al gen a expresar en la posición correcta del sitio aceptor del empalme; además, estaban poliadenilados $(28,103)$. La transfección permanente se logra con la introducción de episomas o por integración de ADN al genoma.
Transfección estable con episomas. Los episomas son vectores circulares de ADN autorreplicativos, que contienen un gen de resistencia a la droga (marcador de selección) además de las secuencias intergénicas y el gen de interés o reportero (figura $2 b$ ). Las células transfectadas son seleccionadas basándose en la resistencia conferida por el marcador de selección, lo cual resulta en el aumento del número de copias del vector y el nivel de la expresión del gen reportero. Entre los marcadores de selección más usados se encuentran los genes neor, hyg y nagt, que codifican para las fosfotransferasas que confieren resistencia a los aminoglicósidos geneticina (G418), higromicina B y a la tunicamicina, respectivamente. También los marcadores sat, que codifica estreptomicina acetiltransferasa, y $\mathrm{pac}^{r}$ y phleo $^{r}$ que confiere resistencia al antibiótico glicopéptido puromicina y fleomicina, respectivamente, han sido usados en transfecciones de promastigotes de diferentes especies de Leishmania (103-107).

Transfección permanente por integración al genoma. Para realizar una transfección permanente por integración de ADN al genoma, el vector de expresión es linearizado con enzimas de restricción dentro de secuencias idénticas a las del sitio propuesto para la integración en el genoma (28). El vector es integrado en una región muda del genoma como los espaciadores del ARNr y del ME, o en el sitio correspondiente al gen a eliminar o complementar (figura 2c; véase sección eliminación de genes).

Dado que Leishmania es un organismo diploide, usualmente se requieren dos o más marcadores durante las transfecciones permanentes para expresar combinación de genes heterólogos o comprobar la eliminación de dos genes o dos alelos simultáneamente. Durante la integración de vectores en el genoma se deben tener en cuenta factores que influyen en la frecuencia de recombinación homóloga entre el vector introducido y las secuencias de ADN cromosómico, como son: la cantidad y naturaleza de secuencias homólogas, el locus genético, el número de copias del blanco y el diseño del vector.

La divergencia entre las secuencias del ADN donador y el blanco reduce la eficiencia de la 
integración de genes en Leishmania. La longitud de la homología entre el vector y las secuencias blanco influye en la frecuencia de recombinación cuando ésta es menor de $1 \mathrm{~kb}$. El tamaño mínimo para una recombinación homóloga eficiente en Leishmania ha sido establecido entre 150-200 pb (110).

La transfección estable ha facilitado la cuantificación de células de Leishmania y ha permitido realizar ensayos para el desarrollo de la terapia con drogas. El gen bacteriano lacZ ( $\beta$ galactosidasa) ha permitido la detección de parásitos en tejidos de ratón hasta 4 semanas después de la infección por medio de una reacción colorimétrica visualizada bajo el microscopio de luz (101). Por otro lado, existe una correlación lineal entre el número de parásitos recombinantes que expresan el gen reportero luc (luciferasa de la luciérnaga Photynus pyralis) y la actividad luciferasa; por ello, la transfección con luc resulta muy útil para vigilar la progresión de infecciones dentro de macrófagos y tejidos hospederos, y la cuantificación rápida y sensible en pruebas de citotoxicidad de drogas por medio de luminometría $(99,100)$.

Igualmente, el nivel de fluorescencia en promastigotes transfectados con gfp (proteína verde fluorescente de la medusa Aequorea victoria) corresponde al número de células inoculadas (101-102). GFP se detecta en animales vivos de una manera no invasiva y se puede visualizar directamente bajo el microscopio de fluorescencia; por ello se ha usado para el análisis en tiempo real de agentes antileishmaniásicos con promastigotes vivos (101). GFP también se ha usado como proteína de fusión (tag) en estudios de localización de proteínas transportadoras en Leishmania y en estudios de interferencia de expresión con ARN en este parásito $(48,115)$.

La transfección estable en Leishmania ha permitido estudiar algunos aspectos de la interacción del parásito con el sistema inmune. Los parásitos que expresan ovoalbúmina y $\beta$ galactosidasa fueron capaces de dirigir estas proteínas reporteras hacia el fagolisosoma, donde fueron procesadas para el reconocimiento por células CD4+, lo cual sugiere que el estudio de las vías procesadoras del complejo mayor de histocompatibilidad clase II usando parásitos de Leishmania modificados podría ser una aproximación valiosa para estudiar aspectos de la interacción parásito-hospedero (105).

Expresión de proteínas foráneas con modificaciones postranscripcionales. Leishmania podría representar una célula útil en el desarrollo de sistemas de expresión de proteínas foráneas biológicamente activas (93-95). Las células de Leishmania fueron capaces de expresar la fosfoproteína humana P53 activa (94) y, por medio de inmunoprecipitación y autorradiografía, se comprobó que el parásito logró llevar a cabo la fosforilación de esta proteína. La P53 sintetizada en Leishmania reconoció la secuencia de su ADN blanco y se comportó muy similarmente a la P53 derivada de células humanas con respecto a la unión con el anticuerpo MbPab 421, lo cual indica que la P53 recombinante producida por la maquinaria de expresión de Leishmania retuvo su habilidad de plegamiento y produjo una conformación nativa.

En otro estudio (93), se produjeron parásitos de L. major que expresan y secretan interferón $\gamma$ activo de ratones (IFN $\gamma$ ) (véase el siguiente subtítulo). Dado que Leishmania es rica en glicoproteínas $(72,76-81,83,88,90)$ también posee el potencial de glicosilar proteínas foráneas. Leishmania combina características atractivas como sistema de expresión de proteínas tanto de origen procariote como de origen eucariote, por la simplicidad del sistema que incluye los requerimientos de cultivo, la construcción de plásmidos, la facilidad de transfección y la selección de células, y al potencial de realizar modificaciones postranscripcionales necesarias en el caso de algunas proteínas de origen eucariote.

Expresión de genes suicidas y creación de cepas atenuadas. La 3'-UTR del gen que codifica la proteína amastigote-específica A2 de L. donovani ha permitido obtener la expresión preferencial de genes en el estadio amastigote. Este elemento regulador ha sido útil en la generación de cepas de Leishmania recombinantes atenuadas. La atenuación se regula al ocurrir la diferenciación 
de promastigote a amastigote. Este sistema promovió la expresión de la timidina cinasa del virus Herpes simplex (HSV-TK), e indujo sensibilidad a la droga anti-herpes ganciclovir en amastigotes y afectó dramáticamente el crecimiento durante la infección in vitro (96). En otro estudio, ratones BALB/c, infectados con $L$. major transfectados con $h s v$-tk se trataron con ganciclovir. La inhibición completa de la replicación de los parásitos intracelulares ocurrió a los 4 días después de la infección, y se obtuvieron niveles de protección, desde parcial a total, contra un reto con L. major virulento, según la dosis de ganciclovir (97). Además, se han efectuado transfecciones en Leishmania con versiones deletéreas de genes que codifican enzimas importantes para el metabolismo y la supervivencia intracelular del parásito, como una versión truncada de la 3' nucleotidasa/nucleasa carente de secuencia señal lo que conllevó a una acumulación de la enzima en el citoplasma donde es tóxica (96).

En otro estudio se efectuó la expresión heteróloga de una versión mutada del gen tryA, que codifica tripanotión reductasa de $T$. cruzi en $L$. donovani. La pérdida de actividad catalítica fue provocada por un cambio efectuado por mutagénesis dirigida en el sitio activo (33). Luego de la activación de los macrófagos con IFN $\gamma$ y lipopolisacárido (LPS) se observó una disminución significativa en la tasa de infección de los parásitos mutantes, en comparación con aquélla de los silvestres dada la participación de try $A$ en la protección de las células contra radicales libres (33). Se inocularon ratones deficientes en células $T$ con $L$. major transfectadas que expresan y secretan IFN $\gamma$ activo de ratones, el cual indujo actividad óxido nítrico sintasa en una línea celular de macrófagos (93). En este caso, los episomas se mostraron estables luego del pase de los parásitos por los ratones en ausencia de presión con droga, y se redujo la progresión de la enfermedad. Puede estudiarse el papel de otras citocinas usando esta aproximación.

La acumulación de productos génicos tóxicos debida a la expresión inducida de genes deletéreos o de genes que promueven la actividad parasiticida de las células hospederas como antígenos protectores o citocinas inmunoestimuladoras, y la pérdida de actividad debida a la expresión de versiones de genes mutados que llevan a la producción de parásitos atenuados, representan herramientas útiles para el desarrollo potencial de vacunas atenuada efectivas.

\section{Eliminación de genes en Leishmania}

El número de genes de Leishmania sometido a análisis, donde el gen es manipulado o eliminado para probar su papel en el ciclo infectivo, crece rápidamente (cuadro 2). Para efectuar la eliminación de un gen completo, los segmentos 3' y 5'-UTR del gen blanco se integran al vector a ambos lados del marcador de selección. El vector es escindido en las uniones de estas secuencias y la integración del marcador ocurre simultáneamente con la eliminación del gen blanco por medio de reemplazo durante la recombinación homóloga. Un knockout de ambas copias del gen blanco requiere de dos rondas de eliminación, con diferentes marcadores de selección. La ausencia del gen se comprueba por técnicas de hibridación. La reexpresión del producto del gen por complemento de los genes eliminados restaura su actividad. La eliminación de genes en Leishmania ha permitido la caracterización de varias moléculas involucradas en el metabolismo celular y el transporte, así como de proteínas transductoras de señal, chaperonas y enzimas involucradas en la virulencia y resistencia a drogas (cuadro 2). También se han evaluado los efectos de la eliminación de dominios esenciales para la actividad enzimática $(31,32)$.

Identificación de genes de virulencia. Muchos de los experimentos de eliminación de genes han llevado a la identificación de genes de virulencia importantes para la supervivencia o la patogénesis del parásito dentro del insecto vector o del hospedero mamífero, mas no para su crecimiento en los medios rutinarios de cultivo (73). Por ejemplo, el gen A2 fue esencial para la supervivencia de $L$. donovani en el macrófago, así como lo fueron la fosfomanomutasa (PMM) para $L$. mexicana y la proteína de choque térmico HSP100 para L. major $(81,84,91)$.

En la categoría de virulentos entran genes que están involucrados en la virulencia pero no la 
explican totalmente, cuya eliminación muestra pérdida cuantitativa pero no completa de virulencia y se puede retener la capacidad de producir lesiones aunque a una tasa más lenta que la de los parásitos de tipo silvestre $(71,74)$. Por ejemplo, la eliminación del arreglo de genes de cisteína proteinasa $(\mathrm{LmCPb})$ en $L$. mexicana redujo la supervivencia intracelular en $80 \%$ (71). Estos mutantes fueron tan eficientes en invadir macrófagos como los de tipo silvestre pero sobrevivieron en menor proporción; además, produjeron lesiones subcutáneas en ratones a tasas más lentas.

En otro estudio observaron que las lesiones inducidas por parásitos mutantes $I m c p b$ se curan acompañadas de respuesta inmune Th1 a diferencia de las inducidas por parásitos de tipo silvestre lo que sugiere que las cisteína proteinasas de $L$. mexicana suprimen la respuesta inmune antileishmania (82). Además, cuando $L$. major fue transfectada con un cósmido que expresa múltiples genes de CPB de L. mexicana, estos parásitos indujeron una respuesta IFN $\gamma$ significativamente inferior comparada con $L$. major silvestre. Estos datos indican que la inhibición de CPB podría probarse como estrategia inmunorreguladora para formas crónicas de leishmaniosis.

Durante los ensayos también ha habido sorpresas. Por ejemplo, la eliminación de GP63, la proteína de superficie más abundante en el promastigote, produjo un efecto pequeño en el fenotipo de $L$. major in vitro (afectó el depósito del complemento) pero no tuvo efecto en las infecciones al insecto, al macrófago o al ratón (75).

Igualmente, la eliminación de los genes que codifican para las proteínas SHERP/HASP (proteína hidrofílica en membrana del retículo endoplásmico y mitocondria/proteína de superficie hidrofílica acilada) abundantes en estadio metacíclico infectivo (64), y la ausencia de proteínas que intervienen en la síntesis de diferentes glicoconjugados implicados en la virulencia tuvieron un efecto pequeño en la pérdida de virulencia $(76,77,80,81,90)$.

Uno de los hallazgos más importantes es que los genes putativos de virulencia no son igualmente activos en todas las especies de Leishmania. En L. major, la eliminación de Ipg1 (gen que codifica para galactofuranosil transferasa) produjo promastigotes específicamente deficientes en la síntesis del mayor componente del glicocálix denso de la superficie de los promastigotes de Leishmania, lipofosfoglicano (LPG) (77). Los mutantes de $L$. major fueron incapaces de sobrevivir en el insecto o de establecer de manera eficiente infecciones en macrófagos o ratón, mientras que la eliminación de $\operatorname{lpg} 1$ en $L$. mexicana no produjo ningún cambio de fenotipo en las infecciones a ratón o macrófago (76). Estos hallazgos muestran que las diferentes especies de Leishmania hacen uso de su repertorio de genes y moléculas potenciales de virulencia a diferentes grados en su interacción con el hospedero.

Identificación de genes esenciales. Los estudios también han llevado a la identificación de genes esenciales cuya pérdida no es tolerable por el organismo y, por ello, son blancos potenciales para el desarrollo de agentes anti-Leishmania (2849). Por ejemplo, la eliminación de N-miristoiltransferasa (NMT) en L. major produjo parásitos no viables (28). Esta enzima cataliza la modificación cotraduccional de proteínas por $\mathrm{N}$ miristoilación, proceso importante para la orientación subcelular y las interacciones proteínaproteína. NMT es expresada constitutivamente en todos los estadios del parásito y podría ser blanco apropiado para el desarrollo de agentes antiLeishmania.

La eliminación de genes esenciales puede producir organismos auxótrofos que requieran factores específicos de crecimiento. Por ejemplo, la eliminación de los genes de enzimas clave en la síntesis de poliaminas, como la espermidina sintasa (SPDSYN) y la ornitina decarboxilasa (ODC), producen promastigotes auxótrofos para poliaminas $(37,46)$, los cuales deben importar espermidina exógena para sobrevivir. Además, el nivel de tripanotión, tiol único en tripanosomátidos que contiene espermidina y que, además, es el componente principal de la defensa antioxidante, también se reduce. Así, estas enzimas esenciales son blancos prometedores para la validación terapéutica. 
Creación de vacunas. Los defectos causados en parásitos de Leishmania atenuados por irradiación u obtenidos de cultivos por medio de pases seriados probablemente son múltiples y aún no están definidos; además, pueden revertir hacia virulencia o persistir por largos períodos. La eliminación de genes hace posible la creación de mutantes no reversibles, los cuales en algunos casos pueden inducir protección contra Leishmania y en otros, controlar el desarrollo de la lesión durante meses, o inducir altos niveles de inmunidad en ratones vacunados con parásitos mutantes y retados luego con parásitos virulentos $(29,42,74)$.

Ya que la secuencia del gen blanco es eliminada, el uso de estos mutantes vivos como vacuna es más seguro. Por ejemplo, macrófagos peritoneales infectados con promastigotes Impk de $L$. mexicana (carentes de LMPK, homóloga de la proteín cinasa activada por mitógeno) son capaces de controlar la infección y erradicar los parásitos; además, los ratones BALB/c infectados con estos mutantes no mostraron desarrollo de lesiones (86). Los promastigotes Impk son una vacuna viva potencial ya que infectan macrófagos, y se transforman a amastigotes promoviendo una respuesta inmune sin causar enfermedad.

\section{Transposones como inactivadores de la expresión génica en Leishmania}

La mutagénesis por medio de transposones se realiza por la introducción de elementos transponibles por inserción inactivando genes codificantes de enzimas esenciales. La maquinaria enzimática para el movimiento está dada por la transposasa. La reacción de transposición ocurre mediante una escisión escalonada en la doble hélice en cada extremo del elemento que lo libera de la molécula donadora, seguida de la ligación del transposón dentro de un corte en el sitio blanco.

Gueiros-Filho y Beverley (98) realizaron la inactivación del gen que codifica para la dihidrofolatorreductasa timidilato sintasa (DHFRTS). Esta enzima posee un papel crucial en el metabolismo de los folatos y, además, cataliza reacciones consecutivas en la síntesis de novo de timidina monofosfato (dTMP). La inactivación se llevó a cabo por la inserción del elemento transponible mariner de Drosophila (Mos1), al transfectar células de $L$. major con dos tipos de plásmidos; uno contenía Mos1, y el otro la región codificadora para la transposasa de los elementos mariner-like (MLE). Las pruebas de hibridización y análisis de secuencia mostraron que $23 \%$ de las células tenía a Mos1 integrado en el genoma al lado del dinucleótido TA en la posición 532 dentro de la región codificadora de dhfr-ts y carecían completamente de la actividad de DHFRTS (98).

\section{Silenciamiento de genes por ARN de interferencia y por ARN antisentido}

\section{ARN de interferencia}

El ARN de interferencia (ARNi) es un mecanismo postranscripcional de silenciamiento de genes en organismos eucariotes a través del cual ARN genespecífico de doble cadena promueve la degradación de transcritos celulares homólogos (116). El ARNi es considerado un mecanismo de defensa contra transcritos aberrantes como aquéllos producidos durante infecciones virales y movilización de transposones. Al entrar en la célula, el ARN de doble cadena es procesado por una nucleasa para producir ARN pequeños de 2125 nt que actúan como secuencias guía para la degradación del ARN blanco y que se han denominado ARN de interferencia pequeños.

Hasta la fecha la interferencia por ARN (ARNi) ha sido útil para la inhibición de la expresión génica en especies de tripanosomas, pero no ha producido inhibición exitosa en Leishmania (115). Se ha reportado la activación del ARNi debida a la expresión regulada o a la transfección de ARN de doble cadena de actina (116) y de la 5'-UTR de $\alpha$-tubulina (117) en T. brucei.

Ngo y colegas descubrieron que la expresión in vivo de la 5'-UTR del ARNm de la $\alpha$-tubulina lleva a la producción de células multinucleadas con alteraciones morfológicas y con bloqueo específico de la citocinesis. La transfección de la 5'-UTR sintética de doble cadena causó el mismo fenotipo. EI ARNm fue degradado rápida y específicamente conllevando a un déficit en la síntesis de tubulina (117).

También se ha reportado el descubrimiento de moléculas abundantes de ARN de interferencia 
de pequeños derivados de transcritos de retroposones en este organismo (116). El hecho de que los ensayos de silenciamiento de genes con ARNi en Leishmania no hayan tenido éxito podría sugerir que Leishmania es por naturaleza deficiente de actividad ARNi endógena.

$A R N$ antisentido. En la naturaleza, el ARN antisentido promueve la formación de moléculas híbridas de ARN de doble cadena que pueden afectar la estabilidad o el procesamiento de los transcritos (empalme, exportación nuclear y unión a ribosomas), interfiriendo con la expresión de productos génicos específicos; por ello, el ARN antisentido transcrito a partir de plásmidos ha sido usado para regular la expresión de genes endógenos (112). En las pruebas de hibridización no se observan trazas del transcrito antisentido, pero sí una disminución acentuada del transcrito endógeno. Se ha realizado la inhibición de la expresión del ARNm de los genes A2 (84) y gp63 (85) usando la expresión episómica de ARN antisentido que demuestra que estos genes representan factores de virulencia. Sin embargo, en el caso de A2, un porcentaje de amastigotes deficientes en ARNm de A2 sobrevivieron en ratón y restauraron la expresión de la proteína A2. La creación de líneas atenuadas de Leishmania para la creación de vacunas por medio de ARN antisentido no es posible ya que no asegura un fenotipo viable y estable.

\section{Complementación y sobreexpresión de genes}

Las aproximaciones genéticas también se han realizado por medio de complementación génica, en la que se empieza a partir de un fenotipo mutante o variante para identificar el gen involucrado $(49,72,76-80,83,88)$. Los genes responsables de los defectos son identificados por una transfección en masa de los mutantes con una librería cósmida de ADN de la especie de Leishmania silvestre y se seleccionan por recobrar la función a través de la complementación.

Una ventaja de este método es que se basa sólo en el fenotipo haciendo que los genes obtenidos sean los directamente implicados en el proceso bajo estudio, a menudo sin que la función haya sido detectada por el análisis de motivos o comparaciones en bases de datos.
Biosíntesis de glicoconjugados. Los mutantes de Leishmania deficientes en LPG fueron el punto de partida para desarrollar los primeros experimentos de complementación génica realizados en parásitos protozoarios. Se desarrolló un protocolo de selección para aislar mutantes defectuosos en la biosíntesis del LPG aprovechando el hecho de que es la única molécula de superficie en $L$. donovanique termina en $\beta$-galactosa, residuo reconocido por la aglutinina de ricino (83). Los genes identificados por complementación fueron lpg1 y lpg2 (transportador de la GDP-manosa a la luz del aparato de Golgi). Los mutantes carentes de ambos genes no sobrevivieron en el ambiente hidrolítico dentro del intestino medio del insecto; además, la unión del parásito al intestino medio del insecto y el mantenimiento de la infección luego de la excreción de la sangre del infectado se vieron comprometidas $(83,88)$. Los estudios subsecuentes han extendido esta aproximación para la identificación de más de 10 genes involucrados en la síntesis de LPG y glicoconjugados relacionados $(72,76-81,90)$.

Mecanismos de resistencia a drogas. En Leishmania, la resistencia se ha asociado con la amplificación génica y gran parte de los estudios de transfección se han enfocado a aclarar los mecanismos de resistencia a drogas (50-70). El locus $\mathrm{H}$, una región de $40 \mathrm{~kb}$ en el ADN genómico, se encuentra amplificado en forma de grandes círculos extracromosómicos, luego de la exposición de las células a varias drogas no relacionadas entre sí (62). Dado que los vectores brindan un método de simulación de la amplificación génica, ha sido posible disecar esta región y localizar genes que confieren resistencia a fármacos. Para identificar los genes que confieren resistencia al arsénico y a los antimoniales, se clonaron fragmentos de la región $\mathrm{H}$ de L. major en un vector de expresión y, luego, se reintrodujeron en el parásito en un alto número de copias confirmando la asociación entre la presencia del gen Impgp A en los constructos y el nivel de resistencia $(51,52)$.

PgpA es un transportador del tipo ABC localizado en la membrana de las vesículas intracelulares, que confiere resistencia a los antimoniales y los 
arsenicales por secuestro de conjugados metaltripanotión $(51,52,54)$. Gracias a la producción de mutantes con deleción o con sobreexpresión se ha podido observar que la resistencia a los antimoniales en Leishmania es multifactorial con contribuciones de varios componentes, que incluyen un sistema diferente de $p g p A$ que permite la salida de metales conjugados con tripanotión y las enzimas implicadas en su síntesis $(\gamma$ glutamilcisteína sintetasa y ornitina decarboxilasa) $(52,55,57,66,67)$.

Se han identificado otros fenotipos asociados con la resistencia a metales y la resistencia cruzada $(50,53,58-60,68,70)$. La localización de los genes responsables de la resistencia a drogas también ha sido posible con mutaciones puntuales que llevan a pérdida (69) o ganancia de la función $(57,58)$.

La pteridín reductasa (PTR1), responsable de la resistencia al metotrexato (MTX) en Leishmania, incrementa el nivel de folatos reducidos a través de una vía alterna, la cual compensa la inhibición de la DHFR-TS por MTX. La actividad PTR1 es esencial para la supervivencia de los parásitos in vitro en medios de cultivo definidos, pero no in vivo debido a que el parásito puede obtener pteridinas reducidas las cuales son sintetizadas de novo por el hospedero mamífero (65). La pérdida de PTR1 lleva a un aumento en la patogénesis en infecciones a ratón ya que eleva la tasa de diferenciación a la forma metacíclica infectiva. PTR1 podría ser blanco para quimioterapia en combinación con inhibidores de la DHFR-TS. Es necesaria una aproximación con múltiples blancos para crear agentes efectivos anti-Leishmania.

Muchas de las enzimas del parásito son potencialmente susceptibles a inhibidores previamente desarrollados en otros sistemas lo que puede ser favorable para su identificación como blancos a través de la selección por drogas. La complementacion y la sobreexpresión de genes son herramientas muy útiles para explorar las respuestas potenciales del parásito a quimioterapia, tanto en términos de los mecanismos principales de resistencia como de los mecanismos compensatorios asociados.

\section{Conclusiones y perspectivas}

Se ha entrado a la nueva era en la investigación de Leishmania. El desarrollo de técnicas de manipulación genética permite el análisis funcional de genes en el contexto del parásito. Dada la importancia del uso de los sistemas de expresión de proteínas para el conocimiento de este parásito, se deben proponer modificaciones que incluyan el desarrollo de vectores de expresión inducibles de manera más eficiente, la definición más rigurosa de los medios de cultivo y la búsqueda de cepas más eficientes para la transfección génica.

El conocimiento de los factores que controlan la expresión génica en Leishmania también es necesario para el desarrollo de herramientas moleculares avanzadas que permitan el estudio de las bases genéticas de infectividad y patogénesis. El campo emergente de la genómica funcional está dedicado al desarrollo y la aplicación de métodos que permitan estudiar de manera eficiente la expresión de varios genes simultáneamente, por las tecnologías de microarreglos y proteómica (119-121).

La genómica funcional y la manipulación genética, apoyadas por la bioinformática, ofrecen herramientas diferentes y complementarias para priorizar los genes en que se deben enfocar estudios más profundos para la validación funcional a la identificación y valoración de nuevos blancos quimio e inmunoterapéuticos.

\section{Agradecimientos}

Este trabajo fue financiado por Colciencias (contratos números 021-2000 y 437-99).

\section{Referencias}

1. Leishmaniasis. http://www.who.int/emc/diseases/leish/ leisdis1.htm

2. Herwaldt B. Leishmaniasis. Lancet 1999;354:1191-9.

3. Lira R, Sundar S, Makharia A, Kenney R, Gam A, Saravia E et al. Evidence that the high incidence of treatment failures in Indian kala-azar is due to the emergence of antimony resistant strains of Leishmania donovani. J Infect Dis 1999;180:564-7.

4. Sundar S. Drug resistance in Indian visceral leishmaniasis. Trop Med Int Health 2001;6:849-54. 
5. Laban A, Wirth D. Transfection of Leishmania enriettii and expression of chloramphenicol acetyltransferase gene. Proc Natl Acad Sci USA 1989;86:9119-23.

6. Curotto de Lafaille M, Laban A, Wirth D. Gene expression in Leishmania: analysis of essential 5' DNA sequences. Proc Natl Acad Sci USA 1992;89:2703-7.

7. Quijada L, Soto M, Alonso C, Requena J. Identification of a putative regulatory element in the 3'untranslated region that controls expression of HSP70 in Leishmania infantum. Mol Biochem Parasitol 2000; 110:79-91.

8. Graham SV. Mechanisms of stage-regulated gene expression in Kinetoplastida. Parasitol Today 1995;11: 217-23.

9. Papadopoulou B, Huang XF, Boucher N, McNicoll F. Stage-specific regulation of gene expression in Leishmania. ASM News 2003;69:282-8.

10. Brittingham A, Miller M, Donelson J, Wilson M. Regulation of GP63 mRNA stability in promastigotes of virulent and attenuated Leishmania chagasi. Mol Biochem Parasitol 2001;112:51-9.

11. Burchmore RJ, Landfear S. Differential regulation of multiple glucose transporter genes in Leishmania mexicana. J Biol Chem 1998;273:29118-26.

12. Flinn H, Smith D. Genomic organization and expression of a differentially-regulated gene family from Leishmania major. Nucleic Acids Res 1992;20:755-62.

13. Argaman M, Aly R, Shapira M. Expresion of heat shock protein 83 in Leishmania is regulated posttranscriptionally. Mol Biochem Parasitol 1994;64:95-110.

14. Charest H, Zhang W, Matlashewski G. The developmental expression of Leishmania donovani A2 amastigote-specific genes is post-transcriptionally mediated and involves elements located in the 3' untranslated region. J Biol Chem 1996;271:17081-90.

15. Kelly BL, Nelson T, McMaster R. Stage-specific expression in Leishmania conferred by 3' untraslated regions of $L$. major leishmanolysin genes (GP63). Mol Biochem Parasitol 2001;116:101-4.

16. Brooks DR, Denise H, Westrop G, Coombs G, Mottram J. The stage-regulated expresion of Leishmania mexicana CPB cysteine proteases is mediated by an intercistronic sequence element. J Biol Chem 2001;276:47061-9.

17. Soto M, Requena J, Jimenez-Ruiz A, Alonso C. The mRNA coding for the nucleosomal protein $\mathrm{H} 2 \mathrm{~A}$ of Leishmania is polyadenylated and has stem-loops at the 3'- end. Nucleic Acids Res 1991;19:4554.

18. Boucher N, Wu Y, Dumas C, Dube M, Sereno D, Breton $\mathrm{M}$ et al. A common mechanism of stateregulated gene expression in Leishmania mediated by a conserved 3'-untranslated region element. J Biol Chem 2002;277:19511-20.
19. Wu Y, El-Fakhry Y, Sereno D, Tamar S, Papadopoulou B. A new developmentally regulated gene family in Leishmania amastigotes encoding a homolog of amastin surface proteins. Mol Biochem Parasitol 2000;110:345-57.

20. Mishra K, Holzer T, Moore L, LeBowitz J. A negative regulatory element controls mRNA abundance of the Leishmania mexicana paraflagellar rod gene PFR2. Eukaryot Cell 2003;2:1009-17.

21. Myung K, Beetham J, Wilson M, Donelson J. Comparison of the post-transcriptional regulation of the mRNAs for the surface proteins PSA (GP46) and MSP (GP63) of Leishmania chagasi. J Biol Chem 2002;277: 16489-97.

22. Gutiérrez JA, Puentes F, Moreno A, Patarroyo ME, Murillo L. Identification of a differentially expressed mRNA in axenic Leishmania panamensis amastigotes. Mem Inst Oswaldo Cruz 2001;96:835-8.

23. Mundodi V, Somanna A, Farrell P, Gedamu L. Genomic organization and functional expression of differentially regulated cysteine protease genes of Leishmania donovani complex. Gene 2002;282:257-65.

24. Boucher N, McNicoll F, Dumas C, Papadopoulou B. RNA polymerase I-mediated transcription of a reporter gene integrated into different loci of Leishmania. Mol Biochem Parasitol 2002;119:153-8.

25. Yu M, Roberts T, Sturm N, Campebell D. In vitro transcription of mutated Leishmania tarentolae spliced leader RNA genes approximates in vivo patterns. Mol Biochem Parasitol 2000;111:391-9.

26. Martínez-Calvillo S, Sunkin S, Yan S, Fox M, Stuart K, Myler P. Genomic organization and functional characterization of the Leishmania major Friedlin ribosomal RNA gene locus. Mol Biochem Parasitol 2001;116:147-57.

27. Gay L, Wilson M, Donelson J. The promoter for the ribosomal RNA genes of Leishmania chagasi. Mol Biochem Parasitol 1996;77:193-200.

28. Price $\mathbf{H}$, Menon $\mathbf{M}$, Panethymitaki C, Goulding D, McKean P, Smith D. Myristoyl-CoA: protein Nmyristoyltransferase, an essential enzyme and potential drug target in kinetoplastid parasites. J Biol Chem 2003; 278:7206-14.

29. Titus R, Gueiros-Filho F, de Freitas L, Beverley S. Development of a safe live Leishmania vaccine line by gene replacement. Proc Natl Acad Sci USA 1995;92: 10267-71.

30. Hassan P, Fergusson D, Grant KM, Mottram J. The CRK3 protein kinase is essential for cell cycle progression of Leishmania mexicana. Mol Biochem Parasitol 2001;113:189-98.

31. Sengupta T, Mukherjee M, Mandal C, Das A, Majumder $\mathbf{H}$. Functional dissection of the $\mathrm{C}$-terminal domain of type II DNA topoisomerase from the 
kinetoplastid hemoflagellate Leishmania donovani. Nucleic Acids Res 2003;31:5305-16.

32. Selvapandiyan A, Duncan R, Debrabant A, Bertholet S, Screenivas G, Negi $\mathbf{N}$ et al. Expression of a mutant form of Leishmania donovani centrin reduces the growth of the parasite. J Biol Chem 2001;276:4325361.

33. Tovar J, Cunningham M, Smith A, Croft S, Fairlamb A. Down-regulation of Leishmania donovani trypanothione reductase by heterologous expression of a trans-dominant mutant homologue: effect on parasite intracellular survival. Proc Natl Acad Sci USA 1998;95: 5311-6.

34. Benzel I, Weise F, Wiese M. Deletion of the gene for the membrane-bound acid phosphatase of Leishmania mexicana. Mol Biochem Parasitol 2000;111:77-86.

35. Zhang K, Showalter M, Revollo J, Hsu F, Turk J, Beverley SM. Sphingolipids are essential for differentiation but not growth in Leishmania. EMBO J 2003;22:6016-26.

36. Flaspohler J, Lemley K, Parsons M. A dominant negative mutation in the GIM1 gene of Leishmania donovani is responsible for defects in glycosomal protein localization. Mol Biochem Parasitol 1999;99:11728.

37. Jiang Y, Roberts S, Jardim A, Cartet N, Shih S, Ariyanayagam $\mathbf{M}$ et al. Ornithine decarboxylase gene deletion mutants of Leishmania donovani. J Biol Chem 1999;274:3781-8.

38. Roberts SC, Scott J, Gasteier JE, Jiang Y, Brooks B, Jardim A et al. S-adenosylmethionine decarboxylase from Leishmania donovani. Molecular, genetic, and biochemical characterization of null mutants and overproducers. J Biol Chem 2002;277:5902-9.

39. Wiese M, Kuhn D, Grunfelder C. Protein kinase involved in flagellar-length control. Eukaryot Cell 2003; 2:769-77.

40. Dole V, Myler P, Stuart K, Madhubala R. Expression of biopterin transporter (BT1) protein in Leishmania. FEMS Microbiol Lett 2002;208:89-91.

41. Cruz A, Beverley S. Gene replacement in parasitic protozoa. Nature 1990;348:171-3.

42. Cruz A, Coburn CM, Beverley S. Double targeted gene replacement for creating null mutants. Proc Natl Acad Sci USA 1991;88:7170-4.

43. Curotto de Lafaille M, Wirth D. Creation of null/ +mutants of the a-tubulin gene in Leishmania enriettii by gene cluster deletion. J Biol Chem 1992;267:2383946.

44. El Fadili A, Kundig C, Ouellette M. Characterization of the folylpolyglutamate synthetase gene and polyglutamylation of folates in the protozoan parasite Leishmania. Mol Biochem Parasitol 2002;124:63-71.
45. Maga JA, Sherwin T, Francis S, Gull K, LeBowitz JH. Genetic dissection of the Leishmania paraflagellar rod, a unique flagellar cytoskeleton structure. J Cell Sci 1999;112:2753-63.

46. Roberts S, Jiang Y, Jardim A, Carter N, Heby O, Ullman B. Genetic analysis of spermidine synthase from Leishmania donovani. Mol Biochem Parasitol 2001; 115:217-26.

47. Hanson S, Adelman J, UlIman B. Amplification and molecular cloning of the ornithine decarboxylase gene of Leishmania donovani. J Biol Chem 1992;267:2350-9.

48. Arastu-Kapur S, Ford E, UlIman B, Carter NS. Functional analysis of an inosine-guanosine transporter from Leishmania donovani. J Biol Chem 2003;278: 33327-33.

49. Vasudevan G, Carter N, Drew M, Beverley S, Sánchez M, Seyfang A et al. Cloning of Leishmania nucleoside transporter genes by rescue of a transport-deficient mutant. Proc Natl Acad Sci USA 1998:95:9873-8.

50. Kündig C, Leblanc E, Papadopoulou B, Ouellette M. Role of the locus and the resistance gene on gene amplification frecuency in methotrexate resistant Leishmania tarentolae. Nucleic Acids Res 1999; 27:3653-9.

51. Ouellette M, Haimeur A, Grondin K, Légaré D, Papadopoulou B. Amplification of ABC transporter gene pgpA and of other heavy metal resistance genes in Leishmania tarentolae and their study by gene transfection and gene disruption. Meth Enzymol 1998; 292:182-92.

52. Anacleto C, Abdo MC, Ferreira AV, Murta S, Romanha A, Fernández $\mathbf{A}$ et al. Structural and functional analysis of an amplification containing a PGPA gene in a glucantime-resistant Leishmania (Viannia) guyanensis cell line. Parasitol Res 2003;90:110-8.

53. Coelho AC, Beverley S, Cotrim P. Functional genetic identification of PRP1, an ABC transporter superfamily member conferring pentamidine resistance in Leishmania major. Mol Biochem Parasitol 2003;130:8390 .

54. Callahan HL, Beverley SM. Heavy metal resistance: a new role for P-glycoproteins in Leishmania. J Biol Chem 1991;266:18427-30.

55. Papadopoulou B, Roy G, Ouellette M. A novel antifolate resistance gene on the amplified $\mathrm{H}$ circle of Leishmania. EMBO J 1992;11:3601-8.

56. Ouellette $\mathbf{M}$, Borst $\mathbf{P}$. Drug resistance and $P$ glycoprotein gene amplification in the protozoan parasite Leishmania. Res Microbiol 1991;142:737-46.

57. Arrebola R, Olmo A, Reche P, Garvey EP, Santi DV, Ruiz-Perez LM. Isolation and characterization of a mutant dihydrofolate reductase-thymidylate synthase from methotrexate-resistant Leishmania cells. J Biol Chem 1994;269:10590-6. 
58. Cotrim PC, Garrity LK, Beverley SM. Isolation of genes mediating resistance to inhibitors of nucleoside and ergosterol metabolism in Leishmania by overexpression/ selection. J Biol Chem 1999;274:37723-30.

59. Liu X, Chang KP. The 63-kilobase circular amplicon of tunicamycin-resistant Leishmania amazonensis contains a functional $\mathrm{N}$-acetylglucosamine-1-phosphate transferase gene that can be used as a dominant selectable marker in transfection. Mol Cell Biol 1992;12: 4112-22.

60. Henderson DM, Sifri CD, Rodgers M, Wirth DF, Hendrickson N, Ullman B. Multidrug resistance in Leishmania donovani is conferred by amplification of a gene homologous to the mammalian $m d r 1$ gene. Mol Cell Biol 1992;12:2855-65.

61. Romero IC, Saravia NG, Walker J. Selective action of fluoroquinolones against intracellular amastigotes of Leishmania (Viannia) panamensis in vitro. Antimicrob Agents Chemother 2004 (enviado para publicación).

62. Segovia M. Leishmania gene amplification: a mechanism of drug resistance. Ann Trop Med Parasitol 1994;88:12330.

63. Beverley SM. Gene amplification in Leishmania. Annu Rev Microbiol 1991;45:417-44.

64. McKean P, Denny P, Knuepfer E, Keen J Smith D. Phenotypic changes associated with deletion and overexpression of a stage-regulated gene family in Leishmania. Cell Microbiol 2001;3:511-23.

65. Bello AR, Nare B, Freedman D, Hardy L. PTR1: a reductase mediating salvage of oxidized pteridines and methotrexate resistance in the protozoan parasite Leishmania major. Proc Natl Acad Sci USA 1994;91: 11442-6.

66. Légaré D, Papadapoulou B, Roy G, Mukhopadhyay R. Haimeur A, Dey $\mathbf{S}$ et al. Efflux systems and increased trypanothione levels in arsenite resistant Leishmania. Exp Parasitol 1997;87:275-82.

67. Ouellette M. Biochemical and molecular mechanisms of drug resistance in parasites. Trop Med Intern Health 2001;6:874-88.

68. Papadopoulou B, Roy G, Ouellette M. Frequent amplification of a short chain dehydrogenase gene as part of circular and linear amplicons in methotrexate resistant Leishmania. Nucleic Acids Res 1993; 21:4305-12.

69. Vasudevan G, UlIman B, Landfear S. Point mutations in a nucleoside transporter gene from Leishmania donovani confer drug resistance and alter substrate selectivity. Proc Natl Acad Sci USA 2001;98:609297.

70. Kink JA, Chang KP. Tunicamycin-resistant variants from five species of Leishmania mexicana amazonensis: expression of virulence associated with an increased activity of $\mathrm{N}$-acetyl glucosaminyl transferase and amplification of its presumptive gene. Proc Natl Acad Sci USA 1987;84:1253-7.

71. Mottram J, Souza A, Hutchison E, Carter R, Frame M, Coombs G. Evidence from disruption of the Imcpb gene array of Leishmania mexicana that cysteine proteinases are virulence factors. Proc Natl Acad Sci USA 1996;93:6008-13.

72. Ilg T, Stierhof YD, Wiese M, McConville MJ, Overath P. Characterization of phosphoglycan-containing secretory products of Leishmania. Parasitology 1994; 108(Suppl.):S63-71.

73. Chang KP, McGwire B. Molecular determinants and regulation of Leishmania virulence. Kinetoplastid Biology and Disease 2002;1:1-7.

74. Alexander J, Coombs G, Mottram J. Leishmania mexicana cysteine proteinase-deficient mutants have attenuated virulence for mice and potentiate a Th1 response. J Immunol 1998;161:6794-801.

75. Joshi P, Kelly B, Kamhawi S, Sacks D, MacMaster W. Targeted gene deletion in Leishmania major identifies leishmanolysin (GP63) as a virulence factor. Mol Bichem Parasitol 2002;120:33-40.

76. Ilg T. Lipophosphoglycan is not required for infection of macrophages or mice by Leishmania mexicana. EMBO J 2000;19:1953-62.

77. Turco S, Späth G, Beverley S. Is lipophpsphoglycan a virulence factor? A surprising diversity between Leishmania species. Trends Parasitol 2001;17:223-6.

78. Garami A, IIg T. The role of phosphomannose isomerase in Leishmania mexicana glycoconjugate synthesis and virulence. J Biol Chem 2001;276:656675.

79. Garami A, Ilg T. Disruption of mannose activation in Leishmania mexicana: GDP-mannose pyrophosphorylase is required for virulence, but not for viability. EMBO J 2001;20:3657-66.

80. Hilley JD, Zawadzki JL, McConville MJ, Coombs GH, Mottram JC. Leishmania mexicana mutants lacking glycosyl phosphatidyl inositol(GPI): protein transamidase provide insights into the biosynthesis and functions of GPI-anchored proteins. Mol Biol Cell 2000; 11:1183-95.

81. Garami A, Mehlert A, llg T. Glycosylation defects and virulence phenotypes of Leishmania mexicana phosphomannomutase and dolicholphosphatemannose synthase gene deletion mutants. Mol Cell Biol 2001;21:8168-83.

82. Buxbaum L, Denise H, Coombs G, Alexander J, Mottram J, Scott P. Cystein protease B of Leishmania mexicana inhibits host Th1 responses and protective immunity. J Immunol 2003;171:3711-7.

83. Ryan K, Garraway L, Descoteaux A, Turco S, Beverley S. Isolation of virulence genes directing surface glycosyl-phosphatidylinositol syntesis by 
functional complementation of Leishmania. Proc Natl Acad Sci USA 1993;90:8609-13.

84. Zhang W, Matlashewski G. Loss of virulence in Leishmania donovani deficient in an amastigote-specific protein, A2. Proc Natl Acad Sci USA 1997;94:8807-11.

85. Chen DQ, Kolli BK, Yadava N, Lu HG, Gilman-Sachs A, Peterson DA. Episomal expression of specific sense and antisense mRNAs in Leishmania amazonensis: modulation of gp63 level in promastigotes and their infection of macrophages in vitro. Infect Immun 2000; 68:80-6.

86. Wiese M, Gorcke I. Homologues of LMPK, a mitogenactivated protein kinase from Leishmania mexicana, in different Leishmania species. Med Microbiol Immunol (Berl) 2001;190:19-22.

87. Gokool S. Sigma 1- and mu 1-Adaptin homologues of Leishmania mexicana are required for parasite survival in the infected host. J Biol Chem 2003;278:29400-9.

88. Sacks D, Modi G, Rowton E, Spath G, Epstein L, Turco S et al. The role of phosphoglycans in Leishmaniasandfly interactions. Proc Natl Acad Sci USA 2000;97: 406-11.

89. Dumas C, Ouellette M, Tovar J, Cunningham ML, Fairlamb AH, Tamar S et al. Disruption of the trypanothione reductase gene of Leishmania decreases its ability to survive oxidative stress in macrophages. EMBO J 1997; 16:2590-8.

90. Wilson K, Collart FR, Huberman E, Stringer JR, Ullman B. Amplification and molecular cloning of the IMP dehydrogenase gene of Leishmania donovani. J Biol Chem 1991;266:1665-71.

91. Hubel A, Krobitsch S, Horauf A, Clos J. Leishmania major Hsp100 is required chiefly in the mammalian stage of the parasite. Mol Cell Biol 1997;17:5987-95.

92. Cunningham ML, Titus RG, Turco S, Beverley SM. Regulation of Differentiation to the infective stage of the protozoan parasite Leishmania major by tetrahydrobiopterin. Science 2001;292:285-7.

93. Tobin J, Reiner S, Hatam F, Zheng S, Leptak C, Wirth D. Transfected Leishmania expressing biologically active IFN- $\gamma$. J Immunol 1993;150:5059-69.

94. Zhang W, Charest H, Matlashewski G. The expression of biologically active human p53 in Leishmania cells: a novel eukaryotic system to produce recombinant proteins. Nucleic Acids Res 1995;23:4073-80.

95. Yan S, Myler P, Stuart K. Tetracycline regulated gene expression in Leishmania donovani. Mol Biochem Parasitol 2001;112:61-9.

96. Ghedin E, Charest H, Zhang W, Debrabant A, Dwyer D, Matlashewski G. Inducible expression of suicide genes in Leishmania donovani amastigotes. J Biol Chem 1998;273:22997-3003.
97. Muyombwe A, Oliver M, Harvie P, Bergeron M, Ouellette M, Papadopoulou B. Protection against Leishmania major challenge infection in mice vaccinated with live recombinant parasites expressing a cytotoxic gene. J Infect Dis 1998;177:188-95.

98. Guerios-Filho F, Beverley S. Trans-kingdom Transposition of the Drosophila element mariner within the protozoan Leishmania. Science 1997;276:1716-9.

99. Sereno D, Roy G, Lemesre J, Papadopoulou B, Ouellette M. DNA transformation of Leishmania infantum axenic amastigotes and their use in drug screening. Antimicrob Agents Chemother 2001;45: 1168-73.

100. Roy G, Dumas C, Sereno D, Wu Y, Singh A, Tremblay MJ et al. Episomal and stable expression of the luciferase reporter gene for quantifying Leishmania spp. infections in macrophages and in animal models. Mol Biochem Parasitol 2000;110:195-206.

101. Okuno T, Goto Y, Matsumoto Y, Otsuka H, Matsumoto Y. Applications of recombinant Leishmania amazonensis expressing egfp or beta-galactosidase gene for drug screening and histopathological analysis. Exp Anim 2003;52:109-18.

102. Chan M, Bulinski J, Cang KP, Fong D. A microplate assay for Leishmania amazonensis promastigotes expressing multimeric green fluorescent protein. Parasitol Res 2003;89:266-71.

103. Laban A, Tobin J, Curotto M, Wirth D. Stable expression of the bacterial neorgene in Leishmania enriettii. Nature 1990;343:572-4.

104. Kelly JM, Ward H, Miles M, Kendall G. A shuttle vector which facilitates the expression of transfected genes in Trypanosoma cruzi and Leishmania. Nucleic Acids Res 1992;20:3963-9.

105. Kelly JM. Trypanosomatid shuttle vectors: new tools for the functional dissection of parasite genomes. Parasitology Today 1995;11:447-51.

106. Freedman DJ, Beverley SM. Two more independent selectable markers for stable transfection of Leishmania. Mol Biochem Parasitol 1993;62:37-44.

107. Kapler G, Coburn C, Beverley S. Stable transfection of the human parasite Leishmania major delineates a 30-kilobase region sufficient for extrachromosomal replication and expression. Mol Cell Biol 1990;10:108494.

108. LeBowitz J, Coburn C, McMahon-Pratt D, Beverley S. Development of a stable Leishmania expression vector and application to the study of parasite surface antigen genes. Proc Natl Acad Sci USA 1990; 87: 9736-40.

109. www.ub.es/biocel/wbc/tecnicas/transfeccion.html

110. Papadopoulou B, Dumas C. Parameters controlling the rate of gene targeting frequency in the protozoan 
parasite Leishmania. Nucleic acids Res 1997;25: 4278-86.

111. Sturm N, Campbell D. The role of intron structures in trans-splicing and cap 4 formation for the Leishmania spliced leader RNA. J Biol Chem 1999;274:19361-7.

112. Lee TI, Young R. Transcription of eukaryotic proteincoding genes. Annu Rev Genet 2000;34:77-137.

113. Lewin B. Initiation of transcription. New York: Oxford University Press; 1997. p.811-42.

114. Patnaik PK. Studies with artificial extrachromosomal elements in trypanosomatids: could specificity in the initiation of DNA replication be linked to that in transcription? Parasitol Today 1997;12:468-71.

115. Robinson KA, Beverly SM. Improvements in transfection efficiency and tests of RNA interference (RNAi) approaches in the protozoan parasite Leishmania. Mol Biochem Parasitol 2003;128:217-28.

116. Ullu E, Djikeng A, Shi H, Tschudi C. RNA interference: advances and questions. Phil Trans R Soc Lond B 2002; 357:65-70.

117. Djikeng A, Shi H, Tschudi C, Ullu E. RNA interference in Trypanosoma brucei: cloning of small interfering RNAs provides evidence for retroposon-derived 24-26 nucleotide RNAs. RNA 2001;7:1522-30.

118. Ngo H, Tschudi C, Gull K, Ullu E. Double-stranded RNA induces mRNA degradation in Trypanosoma brucei. Proc Natl Acad Sci USA 1998;95:14687-92.

119. Akopyants NS, Matlib RS, Bukanova EN, Smeds MR, Brownstein BH, Stormo GD et al. Expression profiling using random genomic DNA microarrays identifies differentially expressed genes associated with three major developmental stages of the protozoan parasite Leishmania major. Mol Biochem Parasitol 2004; 136:71-86.

120.Saxena A, Worthey E, Yan S, Leland A, Stuart K, Myler P. Evaluation of differential gene expression in Leishmania major Friedlin procyclics and metacyclics using DNA microarray analysis. Mol Biochem Parasitol 2003;129:103-14.

121. Almeida R, Gilmartin BJ, McCann SH, Norrish A, Ivens AC, Lawson D et al. Expression profiling of the Leishmania life cycle: cDNA arrays identify developmentally regulated genes present but not annotated in the genome. Mol Biochem Parasitol 2004; 136:87-100. 